\title{
Pengembangan Usaha Kelompok Mutiara Abadi Dengan Sistem Lapak dan Wisata di Dusun Karanggeneng Cangkringan Sleman Daerah Istimewa Yogyakarta
}

\author{
Ety Istriani ${ }^{1}$ \\ Program Studi Manajemen, Fakultas Bisnis \\ Universitas Kristen Duta Wacana \\ Yogyakarta

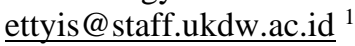 \\ Insiwijati Prasetyaningsih ${ }^{2}$ \\ Program Studi Manajemen, Fakultas Bisnis \\ Universitas Kristen Duta Wacana \\ Yogyakarta \\ insiwijati@staff.ukdw.ac.id $^{2}$
}

\begin{abstract}
Abstrak - Komunitas Mutiara Abadi yang berada di Dusun Karanggeneng Cangkringan Sleman bergerak dibidang sosial dan seni budaya. Kegiatan yang dilakukan memberikan dampingan bagi anak - anak dalam bidang seni budaya ketrampilan dan Pendidikan karakter anak. Kondisi covid 19 menyebabkan berbagai aktivitas berhenti, karena tidak dapat memberikan kompensasi atau uang transpot bagi para pelatih. Disisi lain masyarakat sekitar yang juga orang tua anak - anak membutuhkan tempat untuk melakukan usahanya yang selama ini jualan di taman wisata Kaliurang, dan saat ini wisata Kaliurang juga tutup. Hal tersebut membutuhkan pemikiran bersama agar kegiatan anak - anak tetap berjalan dan usaha masyarakat juga dapat dilakukan. Pemikiran yang muncul adalah mengembangkan sosiopreunership yaitu suatu usaha yang tidak mencari untung semata akan tetapi usaha yang dapat mendukung kegiatan social seni budaya dan meningkatkan penghasilan masyarakat Berdasarkan kondisi tersebut dilakukan pendampingan dengan metode pemberdayaan masyarakat. Melalui pendampingan muncul pemikiran pengembangan usaha dengan sistem lapak yang dipadu dengan wisata yang memanfaatkan kegiatan sosial anak - anak berupa seni budaya tari yang dilakukan oleh anak - anak yang selama ini menjadi kegiatan komunitas tersebut.

Agar usaha tersebut dapat berjalan lancar maka kelompok membutuhkan pengetahuan dan pendampingan wawasan sosial entrepreneurship, organisasi dan manajemen, pemasaran serta analisis usaha dengan sistem lapak yang dikombinasi dengan wisata.
\end{abstract}

Saat ini telah terbentuk usaha lapak yang dapat dimanfaatkan oleh masyarakat. Lapak tersebut disebut lapak "Warung Dhahar Padang Bulan”. mulai berdiri tgl 16 Mei 2021.

Kata Kunci : kata kunci Kewirausahaan sosial, Manajemen \& Organisasi, Pemasaran, Analisis usaha.

Abstract - The Mutiara Abadi Community which is located in Karanggeneng Hamlet, Cangkringan Sleman is engaged in social and cultural arts. The activities provide the assistance for children in the fields of arts and culture, skills and children's character education. The Covid-19 condition caused various activities to stop, because they could not provide compensation or transportation money for the coaches. On the other hand, the surrounding community, including the parents of the children, needs a place to do their business. They have been selling at the Kaliurang tourism park, and currently the tourism in Kaliurang is also closed. This condition needs a careful thought so that children's activities can keep continuing and the business community can also be carried out. Developing sociopreunership, that is a business that is not just looking for profit but a business that can also support social arts and cultural activities and increase people's income needed to be done. Based on these conditions, the assistance was carried out using the community empowerment method through mentoring a business with a stall system combined with tourism. The group needed knowledge and assistance, namely social insight into entrepreneurship, organization and management, marketing and business analysis with a stall system combined with tourism. The outputs to be achieved are 
training materials, community service reports and proceedings articles, the formation of the stalls. Currently, a stall business was established on May 16, 2021 called the "Warung Dhahar Padang Bulan" stall. Keywords: Social Entrepreneurship, Management \&
Organization, Marketing, Business Analysis

\section{PEndahuluan}

Selama ini telah dilakukan pendampingan bagi komunitas Mutiara Abadi dalam seni budaya. Komunitas Mutiara Abadi merupakan kelompok atau komunitas sosial, penggiat sosial mendampingi anak - anak untuk belajar (pendampingan belajar yang disebut pendar), belajar tari, silat dan lain -lain. Masyarakat sekitar mengembangkan kerajinan dari batu seperti cobek, munthu dan produk produk oleh - oleh wisatawan dan menggali pasir dari gunung merapi. Covid - 19 menyebabkan usaha - usaha tersebut terhenti. Disamping itu Kondisi saat ini yaitu gunung merapi sedang bergejolak, maka untuk penambang pasir, saat ini telah dilarang oleh pemerintah. Berdasarkan hal tersebut maka muncul masalah yang dihadapi mitra yaitu membutuhkan alternative penghasilan yang dapat menopang kehidupan keluarga masyarakat sekitar dan kehidupan komunitas berupa pendampingan anak - anak.

Berdasarkan uraian tersebut di atas, maka tim pengabdian bersama mitra melakukan identifikasi alternative usaha sesuai potensi daerah dan masyarakat yang dapat dilakukan untuk meningkatkan kesejahteraan hidupnya. Salah satu yang telah menjadi pemikiran dan bahkan telah dilakukan adalah pembuatan lapak usaha yang dikombinasikan dengan wisata. Disamping itu adanya motivasi masyarakat untuk melakukan usaha sehingga diperlukan pengetahuan kewirausahaan dan kewirausahaan sosial. Kewirausahaan yang akan disosalisaskan dalam pelatihan kelompok ini adalah kewirausahaan social Kewirausahaan sosial atau sering disebut dengan sociopreuneurship, yaitu usaha atau bisnis yang mengedepankan unsur social (1). Kelompok juga membutuhkan peningkatan pengetahuan organisasi, manajemen dan pemasaran serta analisis usaha. Berdasarkan uraian tersebut diatas maka pemberdayaan yang dilakukan adalah peningkatan kapasitas kewiarausahaan sosal, organisasi dan manajemen serta analisis usaha dan pemasaran, baik secara konvensional maupun online.

Perlu juga dijelaskan yang dimaksud dengan lapak adalah membuka tempat (2) berjualan sebagai fasilitas bagi masyarakat untuk menjual barang dagangannya sebagai fasilitas bagi masyarakat. Di daerah karanggeneng yang merupakan daerah wisata Kaliurang, yang selama ini kegiatan yang dilakukan adalah berjualan di daerah wisata, dan selama masa pandemi daerah wisata kaliurang sepi. Berdasarkan kondisi tersebut maka kelompok menciptakan pasar dengan membuat lapak yang dinikmati oleh masyarakat sekitar. Diharapkan masyarakatkan dapat memanfaatkan lapak - lapak tersebut untuk berjualan dengan sistem tertentu yang akan dibuat oleh pengelola lapak dengan pendampingan tim pengabdian masyarakat.

Kegiatan lapak tersebut dikombinasi dengan wisata. Wisata yang dimaksud adalah adanya kegiatan seni yang disajikan oleh anak - anak kelompok komunitas Mutiara Abadi yang selama ini merupakan kegiatan sosial. Kegiatan wisata seni tersebut merupakan inisiatif dari pengelola lapak untuk dapat mengundang orang berkunjung dan berusaha membeli makanan atau barang dagangan yang dijual di lapak tersebut, sehingga tujuan untuk meningkatkan pendapatan dan kesejahteraan masyarakat dapat dicapai.

Masalah:

1. Permasalahan yang dihadapi oleh masyarakat adalah adanya covid 19 yang berpengaruh pada penurunan penghasilan, sehingga membutuhkan terobosan usaha untuk meningkatkan pendapatan.

2. Disamping itu juga permasalahan terbatasnya pengetahuan tentang kewirausahaan, organisasi dan manajemen serta analisis usaha dan pemasaran.

\section{Metode Pelaksanaan}

Metode pelaksanaan pendampingan yang dilakukan dengan cara pemberdayaan masyarakat. Pemberdayaan masyarakat adalah menumbuhkan kesadaran bahwa di lingkungan masyarakat terdapat potensi alam, potensi lingkungan, potensi sumber daya manusia (3). Melalui pemberdayaan ini masyarakat diajak untuk mengenali dan mengatasi masalah yang dihadapinya untuk meningkatkan kesejahteraannya. Aspek penting dalam program pemberdayaan adalah program yang disusun dan dikembangkan sendiri oleh masyarakat yang tidak menciptakan ketergantungan.

Metode yang digunakan dalam pendampingan pemberdayaan adalah dengan menggunakan metode Asset Based Communities Development (ABCD), merupakan konsep pengembangan masyarakat yang didasarkan pada asset lokal yang ada di wilatyah tersebut untuk dikembangkan menjadi lebih produktif (4)

Kelompok Mitra yang selama ini didampingi adalah komunitas Mutiara Abadi berada di lokasi dusun Karanggeneng Umbulharjo Cangkringan Sleman Daerah Istimewa Yogyakarta (DIY). Kelompok telah mengawali kegiatannya dengan kegiatan sosial yaitu kegiatan pendampingan belajar anak, kegiatan seni tari, silat, tempat Pembelajaran Alquran (TPA) dan aktivitas sosial lainnya. Hal tersebut merupakan asset dusun, komunitas yang aktif kreatif. Daerah tersebut merupakan daerah yang menopang wisata Kaliurang, dengan menyewakan jip, berjualan souvenir, oleh - oleh di daerah wisata Kaliurang. Pada masa pandemi seperti saat ini kegiatan wisata berhenti sepi. 
Kondisi tersebut menimbulkan pemikiran untuk mengembangkan masyarakat berdasarkan asset potensi masyarakat yang beraktivitas di daerah wisata.

Teknik - Teknik yang dilakukan dalam melakukan metode pemberdayaan ini adalah teknik pengumpulan data, teknik analisis data dan selanjutnya pelaksanaan kegiatan. Teknik pengumpulan datanya dilakukan dengan wawancara, diskusi, berkunjung ke komunitas, dengan menggunakan zoom, video call dan telephone. Teknik analisis data yang digunakan adalah teknik analisis kualitatif yaitu mengolah data dan informasi dari masyarakat kemudian dibahas untuk mengambil kesimpulan

Berdasarkan teknik tersebut maka diperoleh data - data dan dianalisis sebagai berikut :

Untuk menentukan kegiatan pemberdayaan yang dilakukan, diperlukan informasi atau data - data pendukung, oleh karena itu dilakukan penggalian data informasi tentang kebutuhan dan potensi yang ada dalam komunitas tersebut. Melalui pertemuan online atau video call dilakukan wawancara atau diskusi tentang kebutuhan masyarakat.

a. Dari informasi masyarakat membutuhkan tempat berjualan dan adanya pembeli, karena tempat - tempat wisata sepi bahkan tutup, karena Covid 19. Pembahasan pemikiran keprihatinan pada masa pandemi covid 19, daerah wisata yang tidak ada aktivitas, memerlukan terobosan niat baik (5) yang kreatif untuk menghidupkan kegiatan dengan tetap melakukan protokol kesehatan.

b. Dari diskusi dapat diketahui bahwa tempat berjualan tersebut, jika memungkinkan dapat mendatangkan orang atau pembeli. Pemikiran yang timbul dari kelompok adalah menyediakan lapak bagi masyarakat, sebagai fasilitas untuk berjualan.

c. Usaha lapak \& wisata ini merupakan entrepreneur yang dapat mengubah masa depan (6), karena dalam pembentukan lapak dan wisata tersebut ada beberapa orang - orang yang mendukung untuk terbentuknya lapak dan wisata tersebut, melalui swadaya membangun lapaknya. Walaupun pembiayaan lapak tersebut didanai dengan pinjaman, akan tetapi para pendukung lapak tersebut yang akan mengangsur pinjaman tersebut. Jika usaha lapak \& wisata ini telah menghasilkan keuntungan maka pembayaran pinjaman dibayar melalui sebagaian hasil keuntungan.

d. Untuk melakukan penjulan dengan lapak diperlukan kehadiran masyarakat, oleh karena itu diciptakan aktivitas seni pada momen - momen tertentu, dengan disiplin protokol Kesehatan

e. Selanjutnya agar kegiatan dapat dikelola dengan baik dan berjalan tidak dengan beban yang berat, karena membangun lapak membutuhkan biaya yang cukup besar, dan hal tersebut disediakan dengan swadaya, bisa dianggap sebagai suatu investasi.

f. kelompok membutuhkan pengetahuan tentang mengelola usaha yang antara lain kewirausahaan (7), organisasi dan manajemen (8) serta analisis usaha (9) dan pemasaran. (10)

g. Kegiatan yang dilakukan : (waktu, Materi, kegiatan) :

\begin{tabular}{|c|c|c|c|}
\hline No & Waktu & Materi & Kegiatan \\
\hline 1 & $\begin{array}{l}23 \text { Feb } \\
2021\end{array}$ & $\begin{array}{l}\text { Diskusi } \\
\text { Permasal } \\
\text { ahan } \\
\text { sesuai } \\
\text { kebutuha } \\
\mathrm{n} \\
\text { masyarak } \\
\text { at }\end{array}$ & $\begin{array}{l}\text { Pada masa pandemi } \\
\text { banyak masalah yang } \\
\text { dihadapai, lokasi } \\
\text { komunitas Mutiara } \\
\text { Amadi atau masyarakat di } \\
\text { Karanggeneng } \\
\text { Cangkringan merupakan } \\
\text { lokasi wisata Kaliurang. } \\
\text { Kondisi Wisata Kaliurang } \\
\text { tidak ada aktivitas, } \\
\text { sehingga menghadapai } \\
\text { masalah menurunnya } \\
\text { penghasilan, bahkan tidak } \\
\text { ada penghasilan bagi } \\
\text { masyarakat. Hal tersebut } \\
\text { menuntut pemikiran } \\
\text { terobosan }\end{array}$ \\
\hline 2 & $\begin{array}{l}27 \text { Feb } \\
2021\end{array}$ & Ide usaha & $\begin{array}{l}\text { Pengembangan pemikiran } \\
\text { untuk melakukan } \\
\text { terobosan untuk } \\
\text { membangun ide usaha, } \\
\text { akan tetapi ada } \\
\text { keterbatasan dana } \\
\text { investasi }\end{array}$ \\
\hline 3 & $\begin{array}{l}2 \text { Maret } \\
2021\end{array}$ & $\begin{array}{l}\text { Ide } \\
\text { Usaha }\end{array}$ & $\begin{array}{l}\text { Koordinator komunitas } \\
\text { Nartukiyo } \\
\text { mengembangakn ide } \\
\text { usaha lapak (warung - } \\
\text { warung yang dapat } \\
\text { dimanfaatkan oleh } \\
\text { masyarakat) yang } \\
\text { dikombinasikan dengan } \\
\text { aktivitas wisata berupa } \\
\text { karya seni yang dialkukan } \\
\text { oleh anak - anak sanggar } \\
\text { dan membutuhkan dana } \\
\text { Investasi }\end{array}$ \\
\hline 4 & $\begin{array}{l}9 \text { Maret } \\
2021\end{array}$ & $\begin{array}{l}\text { Sosial } \\
\text { entrepren } \\
\text { eur }\end{array}$ & $\begin{array}{l}\text { Ide Nartukiyo merupakan } \\
\text { sosial entrepreneur dan } \\
\text { kawan - kawan yaitu } \\
\text { menggerakan masyarakat } \\
\text { dengan mengedepankan }\end{array}$ \\
\hline
\end{tabular}




\begin{tabular}{|c|c|c|c|}
\hline & & & $\begin{array}{l}\text { unsur sosial yaitu } \\
\text { menyediakan lapak untuk } \\
\text { masyarakat yang } \\
\text { diharapkan dapat meraih } \\
\text { keuntungan yang } \\
\text { dilakukan secara bagi } \\
\text { hasil (Materi social } \\
\text { Entrepreneur) }\end{array}$ \\
\hline 5 & $\begin{array}{l}16 \\
\text { Maret } \\
2021\end{array}$ & $\begin{array}{l}\text { Sosial } \\
\text { entrepren } \\
\text { eur dan } \\
\text { sosial } \\
\text { investor }\end{array}$ & $\begin{array}{l}\text { Pendampingan dengan } \\
\text { membuat contoh Analisis } \\
\text { Usaha, dan berdasarkan } \\
\text { perhitungan terlampir, } \\
\text { ternyata membutuhkan } \\
\text { dana yang cukup besar } \\
\text { sehingga butuh sosial } \\
\text { investor (Materi Analisis } \\
\text { kebutuhan dana) }\end{array}$ \\
\hline 6 & $\begin{array}{l}24 \\
\text { Maret } \\
2021\end{array}$ & $\begin{array}{l}\text { Sumber } \\
\text { Dana } \\
\text { Untuk } \\
\text { Investasi }\end{array}$ & $\begin{array}{l}\text { Pendampingan, } \\
\text { memberikan wawasan } \\
\text { pengembangan usaha, } \\
\text { kemungkinan mencari } \\
\text { sumber dana, antara lain } \\
\text { kredit koperasi Wadah } \\
\text { untuk usaha }\end{array}$ \\
\hline 7 & $\begin{array}{l}28 \\
\text { April } \\
2021\end{array}$ & $\begin{array}{l}\text { Sumber } \\
\text { Dana } \\
\text { untuk } \\
\text { Investasi }\end{array}$ & $\begin{array}{l}\text { Pendampingan, } \\
\text { memberikan wawasan } \\
\text { sumber dana dari } \\
\text { perbankan BPD, BNI, } \\
\text { KUR } \\
\text { Penjajagan sumber dana } \\
\text { terus diupayakan }\end{array}$ \\
\hline 8 & $\begin{array}{l}4 \mathrm{Mei} \\
2021\end{array}$ & $\begin{array}{l}\text { Pemasara } \\
n\end{array}$ & $\begin{array}{l}\text { Pelatihan atau wawasan } \\
\text { pemasaran materi } \\
\text { terlampir. Berdasarkan } \\
\text { pemasaran telah dipahami } \\
\text { bahwa yang } \\
\text { dikembangkan saat ini } \\
\text { adalah pemasaran dengan } \\
\text { cara mengundang orang } \\
\text { melalui tampilan seni } \\
\text { budaya yang memang } \\
\text { dimiliki oleh komunitas } \\
\text { tersebut. } \\
\text { Untuk pemasaran yang } \\
\text { perlu dikembangkan } \\
\text { adalah pelayanan bagi } \\
\text { para pembeli, baik } \\
\text { pembeli berkunjung } \\
\text { maupun pembeli online } \\
\text { dengan batasan jarak } \\
\text { lingkungan sekitar } \\
\text { (Materi Pemasaran } \\
\text { Usaha) }\end{array}$ \\
\hline
\end{tabular}

\begin{tabular}{|c|c|c|c|}
\hline 9 & $\begin{array}{l}5 \text { Mei } \\
2021\end{array}$ & $\begin{array}{l}\text { Tindak } \\
\text { lanjut } \\
\text { dari } \\
\text { analisis } \\
\text { usaha }\end{array}$ & $\begin{array}{l}\text { Respon analisis usaha } \\
\text { dari komunitas, dengan } \\
\text { membuat sistem usaha } \\
\text { yang diusulkan atau yang } \\
\text { dipikirkan oleh } \\
\text { komunitas }\end{array}$ \\
\hline 10 & $\begin{array}{l}6 \text { Mei } \\
2021\end{array}$ & $\begin{array}{l}\text { Tindak } \\
\text { lanjut } \\
\text { dari } \\
\text { analisis } \\
\text { usaha }\end{array}$ & $\begin{array}{l}\text { Pendampingan, } \\
\text { perhitungan angsuran dari } \\
\text { berbagai alternative } \\
\text { sumber dana, catatan } \\
\text { terlampir }\end{array}$ \\
\hline 11 & $\begin{array}{l}7 \mathrm{Mei} \\
2021\end{array}$ & $\begin{array}{l}\text { Alternatif } \\
\text { sumber } \\
\text { dana }\end{array}$ & $\begin{array}{l}\text { Lanjutan pembahasan } \\
\text { alternative sumber dana } \\
\text { dengan membahas } \\
\text { angsuran dari berbagai } \\
\text { sumber dana dan yang } \\
\text { dipilih dari Bank Sleman } \\
\text { dengan bunga rendah, } \\
\text { catatan terlampir }\end{array}$ \\
\hline 12 & $\begin{array}{l}10 \mathrm{Mei} \\
2021\end{array}$ & $\begin{array}{l}\text { Manajem } \\
\text { en Usaha }\end{array}$ & $\begin{array}{l}\text { Pemberian Wawasan } \\
\text { Manajemen : manajemen } \\
\text { usaha dan manajemen } \\
\text { komunitas. Materi } \\
\text { Manajemen Umum }\end{array}$ \\
\hline 13 & $\begin{array}{l}12 \mathrm{Mei} \\
2021\end{array}$ & & $\begin{array}{l}\text { Pendampingan sistem } \\
\text { pengelolaan: } \\
\text { Perencanaan } \\
\text { Pelaksanaan } \\
\text { Evaluasi } \\
\text { Tindak lanjut }\end{array}$ \\
\hline 14 & $\begin{array}{l}14 \mathrm{Mei} \\
2021\end{array}$ & & $\begin{aligned} & \text { Pendampingan } \\
& \text { pelaksanaan } \\
& \text { 1. } \text { Evaluasi } \\
& \text { perencanaan \& } \\
& \text { Hasil } \\
& \text { 2. } \text { Tindak lanjut } \\
& \text { evaluasi } \\
& \text { 3. } \text { Pembuatan } \\
& \text { perencanaan } \\
& \text { lanjut }\end{aligned}$ \\
\hline 15 & $\begin{array}{l}14 \mathrm{Mei} \\
2021\end{array}$ & $\begin{array}{l}\text { Organisa } \\
\text { si, untuk } \\
\text { mengelol } \\
\text { a lapak } \\
\text { selanjutn } \\
\text { ya } \\
\text { dibentuk } \\
\text { semacam } \\
\text { Usaha } \\
\text { Bersama }\end{array}$ & $\begin{array}{l}\text { Pendampingan } \\
\text { pengelolaan organisasi } \\
\text { Usaha Bersama : } \\
\text { membentuk pengurus } \\
\text { usaha sebagai berikut : } \\
\text { Ketua : Nartukiyo } \\
\text { Sekretaris : Dwi Yuniato } \\
\text { Bendahara : } \\
\text { Suhandani } \\
\text { Anggotanya : } 12 \text { orang } \\
\text { Materi Pengorganisasian }\end{array}$ \\
\hline 16 & $\begin{array}{l}15 \mathrm{Mei} \\
2021\end{array}$ & $\begin{array}{l}\text { Persiapan } \\
\text { pembent } \\
\text { ukan }\end{array}$ & $\begin{array}{l}\text { Dilakukan identifikasi } \\
\text { barang yang akan dijual } \\
\text { di lapak tersebut, dan }\end{array}$ \\
\hline
\end{tabular}




\begin{tabular}{|c|c|c|c|}
\hline & & $\begin{array}{l}\text { warung } \\
\text { dhahar } \\
\text { padang } \\
\text { bulan }\end{array}$ & $\begin{array}{l}\text { direncanakan beberpa } \\
\text { makanan yaitu : } \\
\text { 1. Sate } \\
\text { 2. Tongseng } \\
\text { 3. Soto } \\
\text { 4. Camilan } \\
\text { 5. Dawet } \\
\text { Diawali dengan jualan } \\
\text { dawet, yang dilakukan } \\
\text { oleh salah satu anggota } \\
\text { usaha bersama tersebut }\end{array}$ \\
\hline 17 & $\begin{array}{l}15 \mathrm{Mei} \\
2021\end{array}$ & $\begin{array}{l}\text { Pembaha } \\
\text { san } \\
\text { keterlibat } \\
\text { an } \\
\text { relawan } \\
\text { dalam } \\
\text { warung } \\
\text { Dhahar } \\
\text { Padang } \\
\text { Bulan }\end{array}$ & $\begin{array}{l}\text { Keterlibatan para relawan } \\
\text { belajar etika memberikan } \\
\text { pelayanan pada } \\
\text { konsumen (hospitality), } \\
\text { belajar jiwa wirausaha } \\
\text { (kerja keras, jujur, dan } \\
\text { kemandirian) }\end{array}$ \\
\hline 18 & $\begin{array}{l}16 \text { Mei } \\
2021\end{array}$ & $\begin{array}{l}\text { Terbentu } \\
\text { k usaha } \\
\text { warung } \\
\text { Dhahar } \\
\text { Lapak } \\
\text { "Padang } \\
\text { Bulan" }\end{array}$ & $\begin{array}{l}\text { Usaha lapak Warung } \\
\text { Dhahar Padang Bulan } \\
\text { tersebut merupakan } \\
\text { temapt belajar relawan } \\
\text { tentang kewirausahaan, } \\
\text { dan pengelolaan atau } \\
\text { manajemen usaha } \\
\text { bersama. Warung Dhahar } \\
\text { Padang Bulan tersebut } \\
\text { diresmikan atau dibuka } \\
\text { pada tgl } 16 \text { Mei } 2021\end{array}$ \\
\hline 19 & $\begin{array}{l}18 \mathrm{Mei} \\
2021\end{array}$ & & $\begin{array}{l}\text { Pendampingan bahas } \\
\text { Usaha Bersama (UB) } \\
\text { untuk mendukung usaha } \\
\text { lapak, yaitu para } \\
\text { pedagangnya }\end{array}$ \\
\hline 20 & $\begin{array}{l}25 \mathrm{Mei} \\
2021\end{array}$ & & $\begin{array}{l}\text { Pendampingan wawasan } \\
\text { UB : fungsi \& Manfaat }\end{array}$ \\
\hline 21 & $\begin{array}{l}31 \mathrm{Mei} \\
2021\end{array}$ & & $\begin{array}{l}\text { Pembentukan pengurus } \\
\text { UB }\end{array}$ \\
\hline 22 & $\begin{array}{l}\text { 30 Juni } \\
2021\end{array}$ & & $\begin{array}{l}\text { Pada Bulan Juni telah } \\
\text { dilakukan evaluasi usaha, } \\
\text { dan dapat diketahui } \\
\text { bahwa: } \\
\text { 1. } \\
\text { Usaha belum } \\
\text { surplus } \\
\text { 2. } \\
\text { Masih belajar } \\
\text { melakukan } \\
\text { persediaan } \\
\text { bahan, dan } \\
\text { pengolahan } \\
\text { makanan }\end{array}$ \\
\hline
\end{tabular}

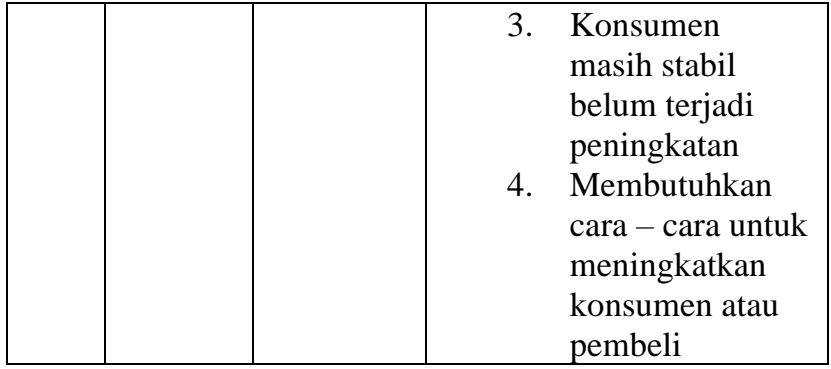

\section{HASIL DAN PEMBAHASAN}

Berdasarkan data - data tersebut maka dilakukan pembahasan bahwa kebutuhan tempat berjualan, berupa lahan dipinggir jalan, agar setiap orang yang lewat dapat melihat dan memungkinkan untuk melihat jualannya. Selanjutnya diidentifikasi ketersediaan lahan, dan lahan yang tersedia berada di lahan salah satu warga. Selanjutnya diidentifikasi bagaimana cara menghadirkan orang agar tertarik ke lokasi tersebut. Kelompok Mutiara Abadi yang selama ini mendampingi masyarakat memiliki anak - anak yang selalu berlatih tari dan senibudaya lainnya. Untuk itu maka kelompok akan mendukung usaha melalui tampilan anak - anak dalam menari atau bersenibudaya.

Berdasarkan analisis data tersebut maka ditentukan usahanya berupa usaha lapak, sebagai social entrepreneur (11) Lapak merupakan tempat berjualan berbagai produk dari beberapa pedagang dan Sebagian besar usaha kuliner. Lapak tersebut dikombinasi dengan penampilan anak - anak untuk mendatangkan orang dengan syarat protocol Kesehatan yang ketat. Nama lapaknya disebut lapak Warung Dhahar Padang Bulan" (WDPB).

Warung Dhahar Padang Bulan tersebut mengkoordinir komunitas untuk beraktivitas dalam WDPB untuk belajar berwirausaha tetapi tetap dapat beraktvitas seni dalam komunitas yang selama ini dilakukan, bahkan WDPB ini akan berkontribusi pada komunitas Seni Komunitas Mutiara Abadi. Pelatihan - pelatihan yang diperlukan dalam usaha tersebut adalah:

a. Pelatihan wawasan kewirausahaan social. Kewirausahaan sosial merupakan usaha yang tidak mengedepankan profit akan tetapi mengedepankan fungsi sosial dan profit adalah dampak dari kinerja dan kapasitas.

b. Organisasi dan pembentukan pengelola atau pengurusOrganisasi diatur agar kegiatan dapat berjalan dengan baik maka ditentukan kepengurusan untuk menentukan pembagian kerja dan tanggungjawab

c. Manajemen.

Pelatihan tentang pengelolaan usaha agar dapat berjalan dengan baik

d. pemasaran 
Pelatihan tentang memasarkan suatu barang dan jasa e. analisis usaha.

\section{KESIMPULAN}

Berdasarkan kegiatan yang telah dilakukan dapat disimpulkan

1. Masyarakat menjadi berdaya, bermartabat, tangguh, mandiri dengan melakukan swadaya usaha berupa lapak warung Dhahar Padang Bulan

2. Materi pelatihan :
a. Pelatihan dengan materi kewirausahaan sosial
b. Pelatihan organisasi \& pembentukan pengelola
c. Pelatihan manajemen
d. Pelatihan manajemen pemasaran
e. Analisis usaha

3. Pendampingan

Pendampingan yang dilakukan berupa pertemuan diskusi, koordinasi, komunikasi dan saling bertukar informasi, secara online atau offline, sehingga dibukanya warung dhahar padang bulan tgl 16 Mei 2021

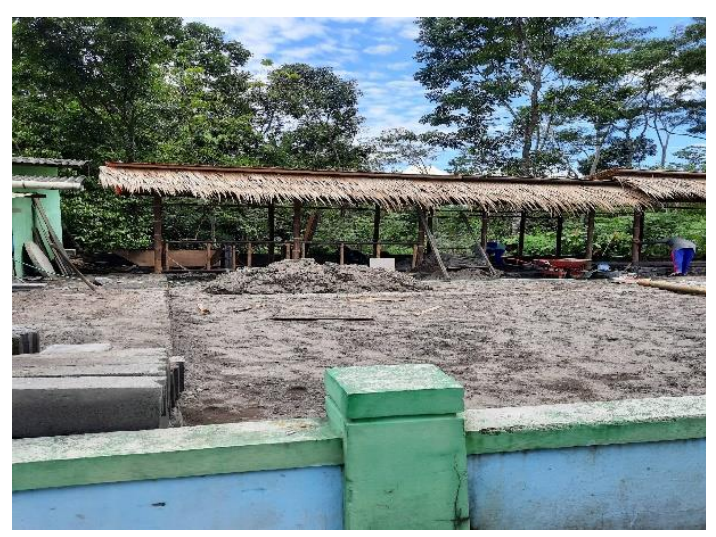

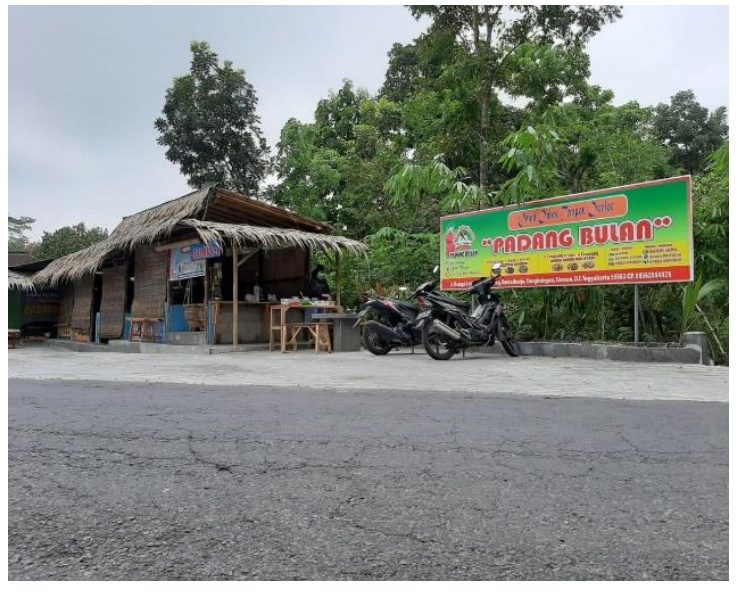
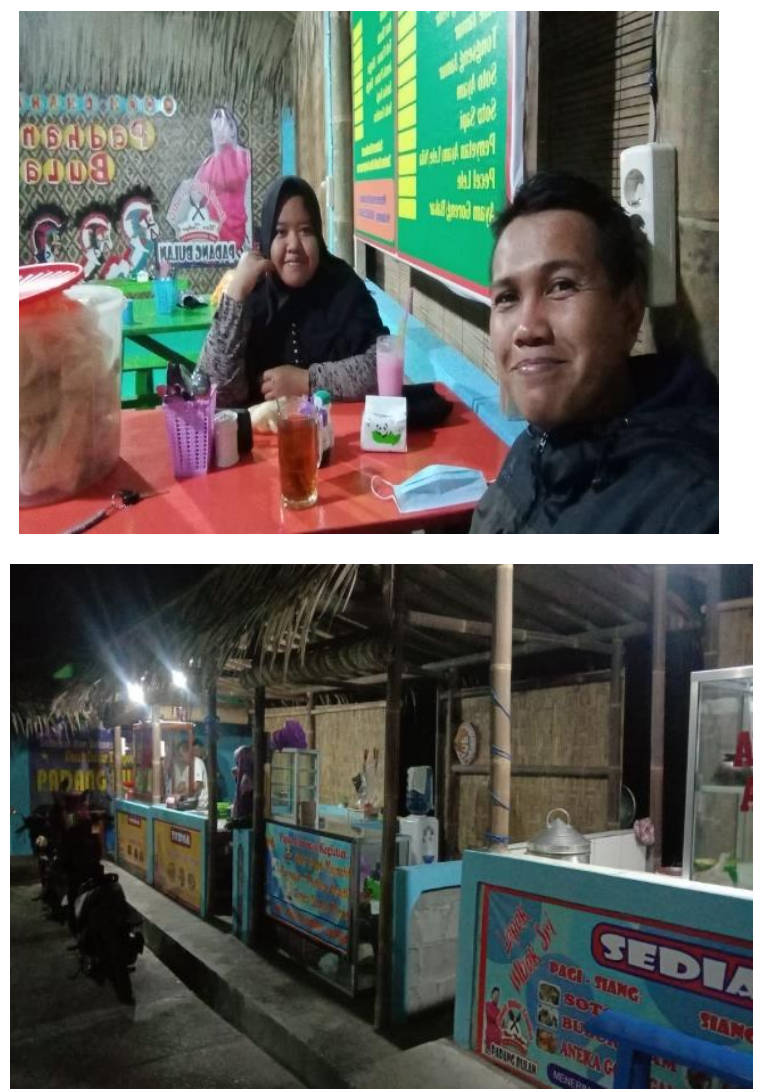


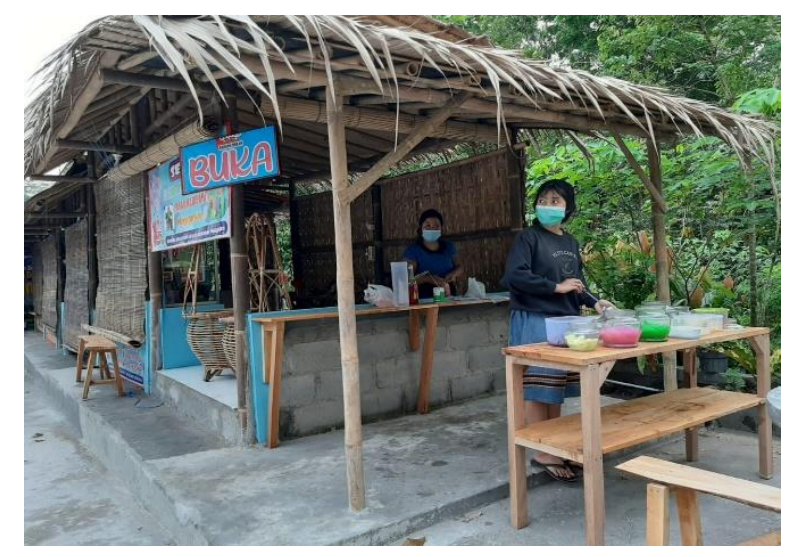

\section{UCAPAN TERIMA KASIH}

Diucapkan terima kasih kepada fakultas Bisnis yang telah mendukung dan memberikan kesempatan untuk melakukan pemberdayaan masyarakat di komunitas Mutiara Abadi di Dusun Karanggeneng Cangkringan Sleman DIY.

\section{DAFTAR PUSTAKA}

[1] Admin AKM, 1 April 2019: Bagaimana Social Entrepreneurship Tumbuh dan Berkembang di Welfare State? https://akmindonesia.org/article/3/bagaimana-social-entrepreneurshiptumbuh-dan-berkembang-di-welfare-state

[2] (https://lektur.id/arti-lapak/ diakses 2021

[3] Hasan. M, M Aziz, 2018. Pembangunan Ekonomi \& Pemberdayaan Masyarakat : Strategi Pembangunan Manusia dalam Perspektiof Ekonomi Lokal, 2018. Eprint.unm.ac.id

[4] http://digilib.uinsby.ac.id diakses 2021

[5] Blog Yoga Permana Wijaya, Niat Baik saja Tidak Cukup, 3 Agustus 2017, https://yogapermanawijaya.wordpress.com/2017/08/03/niatbaik-saja-tidak-cukup/

[6] Maskur Anhari, 2018, Resep Bisnis Ciputra, Mengubah kotoran dan rongsokan menjadi emas,

https://www.google.co.id/search?tbm=bks\&hl=id\&q=quantum+leap+t erbaru+ciputra.

[7] Shandy, Kunthi Fahmar, 2020 Ingin Jadi Wirausaha Sosial yang Sukses? Begini 5 Kuncinya,

https://economy.okezone.com/read/2020/10/24/455/2298889/inginjadi-wirausaha-sosial-yang-sukses-begini-5-kuncinya Ibrahim, Tatang 2021, Manajemen Mutu Terpadu, penerbit Yrama 8] Widya

Sasongko, Catur, 2017, Anggaran, penerbit Salemba Empat

[9] Kotler, Phillip 2020, Principle Of Marketing edisi 8, Prentice Hall, Inc

[10] Dewi, Herlina P, Entrepreneur Talks : Tujuh Strategi Mengembangkan Bisnis, Penerbit Stiletto

[11] 